\title{
Persistent ductus arteriosus in Malaysian patients
}

\author{
M. Krishnan and M. R. J. Snelling \\ From the Lady Templer Hospital, Kuala Lumpur, Malaysia
}

The management of 194 Malaysian patients, clinically diagnosed as persistent ductus arteriosus, is presented. Emphasis is placed on what can be achieved without special investigations. The diagnosis, symptomatology, and surgical findings of the 183 patients undergoing ductal interruption are described. The other II (6\%) showed an error in diagnosis. Associated cardiac lesions were present in 6 of these $(3 \%)$. An interesting feature in the series is that all patients above 30 years were multiparous women.

The importance of ductus arteriosus in prenatal life is well known. Its continued patency in postnatal life and its deleterious effects on the normal life span of an individual have been reported upon by Maude Abbott (1927).

During the 12-year period from May 1958 to April 1970, 194 patients underwent an operation for persistent ductus arteriosus. In I I of them there were errors of diagnosis which are described under the results of operation. Table I shows the age, sex, and race distribution in the 183 patients who actually had ductal interruption. Malaysia is a multiracial country consisting of equal numbers of Malays and Chinese and about ro per cent of Indians. It shows also the characteristic female preponderance.

\section{Symptomatology}

One-hundred-and-forty-eight patients presented with symptoms directly attributable to a persistent ductus arteriosus. The remaining 35 patients were asymptomatic and were discovered on routine examination. The pre-

TABLE I Age, sex, and race of patients

\begin{tabular}{|c|c|c|c|c|c|}
\hline $\begin{array}{l}\text { Age groups } \\
(y r)\end{array}$ & $\begin{array}{l}\text { No. of } \\
\text { patients }\end{array}$ & Race & No. & Sex & No. \\
\hline $0-4$ & $2 \mathrm{I}$ & Chinese & 127 & Male & 52 \\
\hline $5-10$ & 74 & Malays & 29 & Female & I3I \\
\hline I I-20 & 55 & Indians & 23 & Total & 183 \\
\hline $2 I-30$ & 25 & Others & 4 & & \\
\hline $3 I-50$ & 7 & Total & 183 & & \\
\hline Above 50 & I & & & & \\
\hline
\end{tabular}

Received 6 November 1970. senting symptoms of patients could broadly be classified as follows.

(I) Pulmonary symptoms: recurrent episodes of cough, fever, and bronchitis in 52 patients.

(2) Cardiac symptoms: exertional dyspnoea, oedema of the feet, chest pain, and palpitation in 45 patients.

(3) A combination of both pulmonary and cardiac symptoms in 46 patients.

(4) Failure to thrive: poor physical growth and delayed milestones in 5 patients.

Two patients presenting with pulmonary symptoms were found to have pulmonary tuberculosis and were initially treated for this disease before having their ductus interrupted. One underwent pulmonary resection on the right lung after ductal ligation. One patient presented with features of rubella syndrome and another with Marfan's syndrome.

\section{Diagnosis}

The diagnosis of persistent ductus arteriosus in all cases was made clinically. Reliance was placed entirely on the presence of the characteristic continuous murmur, heard maximally over the pulmonary orifice, usually in the second left intercostal space. A thrill was often felt in the same region. The murmur was heard on numerous occasions all over the praecordium particularly in thin patients. It could also be heard in the abdomen and posteriorly in the interscapular region. Only 94 patients had a pulse pressure of $50 \mathrm{mmHg}$ or more.

On chest $x$-ray 79 patients showed the characteristic triad of cardiac enlargement, 
pulmonary plethora, and an enlarged pulmonary conus (see Fig.). Radiologically 80 patients revealed only two of the above features. Twenty-four patients presented with a normal chest $x$-ray and of these II were asymptomatic.

\section{Results of operation}

Out of the 194 patients operated upon, I83 were found to have a persistent ductus. The standard approach via a left posterolateral thoracotomy was employed in all cases. The mode of ductal interruption by ligation was employed in 130 patients during the earlier years (H.M. McGladdery). In 53 the ductus was divided as a matter of preference by one of us (M.K.). Two patients had an intrapericardial ductus.

In I05 patients the ductus was less than I $\mathrm{cm}$ in diameter. In 67 the ductus was wide above $\mathrm{I} \mathrm{cm}$ in diameter, and in a further 5 the ductus had no length at all. In the remaining 6 of the 183 patients the size of the ductus was not recorded.

After ductal interruption, additional cardiac lesions were noted in 6 patients: 2 had aortic valve lesions, 3 had a ventricular septal defect, and I had a partial juxta ductal coarctation of the aorta, requiring no correction.

The remaining II patients submitted to left thoracotomy for a persistent ductus arteriosus did not have this condition. One had a coronary artery fistula, 5 were thought to have aorticopulmonary windows, 2 had an aortic valve lesion, and the remaining 3 a ventricular septal defect with aortic incompetence.

Operative mortality and morbidity Two patients died of uncontrollable haemorrhage during operation from tears of the ductus, one during ductal division and another during ductal ligation. Another patient died in the postoperative period from an error in fluid replacement and postoperative sedation. There were no mishaps among the II patients who underwent thoracotomy only.

No complications of any significance occurred from operation in this series except in one patient, a 19-year-old boy who developed neurological symptoms after ductal division. Lumbar puncture revealed blood in the cerebrospinal fluid. He made a complete recovery in a fortnight. A review one year later revealed that he was well and working. On hourly observation his postoperative blood pressure had not exceeded $130 \mathrm{mmHg}$ systolic. He presumably had a leaking berry aneurysm.

Follow-up As our patients are drawn from all over Malaysia, involving in some instances travel of a few hundred miles, it is not surprising that a complete follow-up of our postoperative patients has not been possible. In addition, the sense of well-being after operation keeps patients away from their doctors. Therefore, follow-up has been possible in only 48 patients.

All these 48 patients are well and leading

FIG. X-rays of patients with persistent ductus arteriosus showing cardiopulmonary changes from mild to severe degree.

(a)

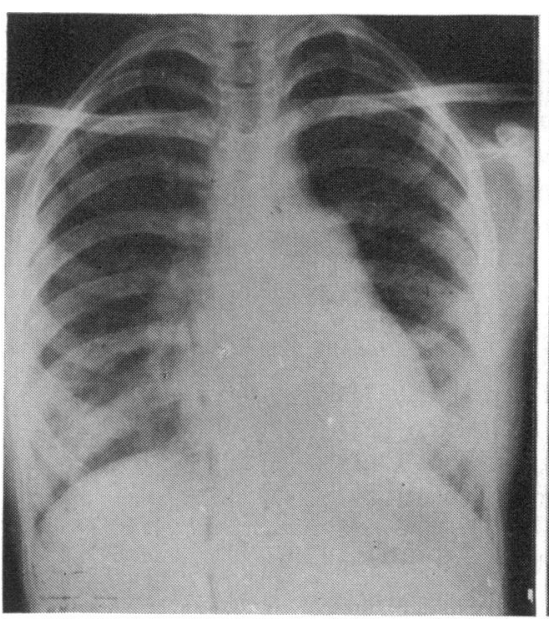

(b)
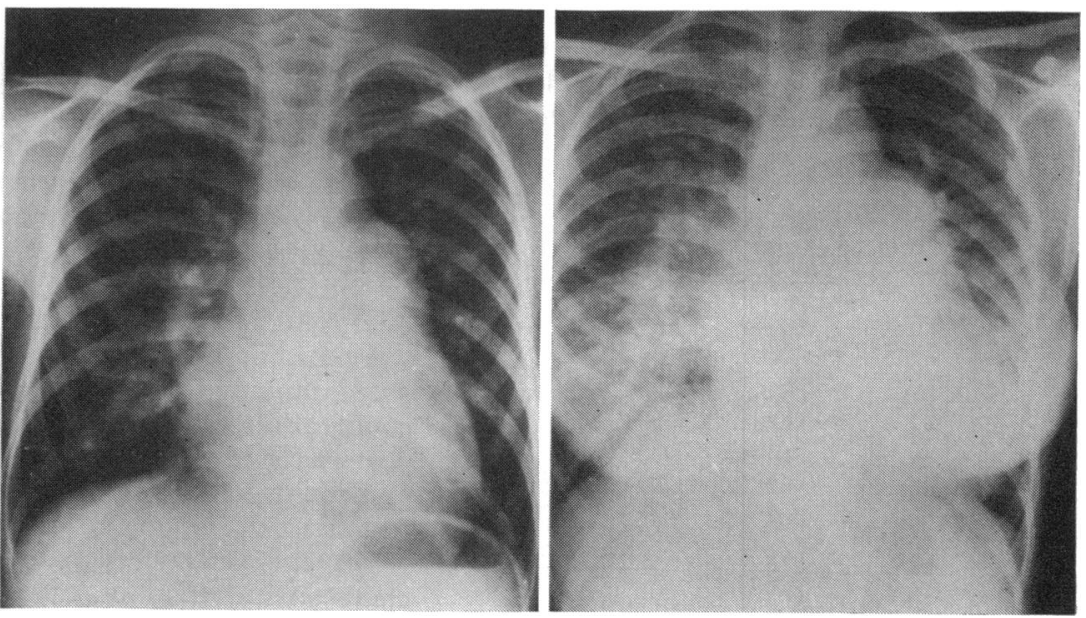
TABLE 2 Length of follow-up of 48 patients

\begin{tabular}{ll}
\hline $\begin{array}{l}\text { Period of } \\
\text { follow-up }(y r)\end{array}$ & $\begin{array}{l}\text { No. of } \\
\text { patients }\end{array}$ \\
\hline$<\mathrm{I}$ & 20 \\
$\mathrm{I}-3$ & I I \\
$3-5$ & I \\
$>5$ & 6 \\
\hline
\end{tabular}

normal lives. Those with symptoms were rendered asymptomatic and children previously failing to thrive showed remarkable progress in normal growth and mental alertness.

\section{Discussion}

Since no cardiac catheterization facilities were available, diagnosis of persistent ductus arteriosus was made on clinical grounds alone and an error of 6 per cent accrued. However, in all these patients an error was anticipated preoperatively. Submission to a left thoracotomy was ventured upon boldly because of the absence of diagnostic aids in this country.

Six patients were found to have an additional cardiac lesion $(3 \%)$. These lesions were unsuspected clinically before operation.

Most of the patients operated upon were between 5 and ro years: only 21 children were under 5 years. Though Crafoord, Mannheimer, and Wiklund (1944) considered that a wide ductus was normally associated with a high pulse pressure, of the 67 patients in this series with a ductus diameter of $I \mathrm{~cm}$ or more, only $4 \mathrm{I}$ patients $(6 \mathrm{I} \%$ ) had a pulse pressure of $50 \mathrm{mmHg}$ or more.

An interesting observation in this series is that all the patients above 30 years of age were multiparous women. Four went through 5 pregnancies without incident, two bore 9 children each without difficulty, and a 58year-old woman (the oldest patient in the series) went through 16 pregnancies and has 13 children alive and well. Four out of these 8 women had a ductus more than $\mathrm{I} \mathrm{cm}$ in diameter.

We wish to thank Mr. H. M. McGladdery whose findings in 130 cases of persistent ductus arteriosus, which were ligated, are reported in this paper.

\section{References}

Abbott, M. E. (1927). Congenital cardiac disease. In Modern Medicine, ed. by W. Osler, 3rd ed., reedited by T. McCrae, Vol. 4, p. 612. Lea and Febiger, Philadelphia.

Crafoord, C., Mannheimer, E., and Wiklund, T. (1944). The diagnosis and treatment of patent ductus arteriosus (Botalli), in connection with 20 operated cases. Acta Chirurgica Scandinavica, 91, 97. 